\title{
Strain management of AIGaN-based distributed Bragg reflectors with GaN interlayer grown by metalorganic chemical vapor deposition
}

Yuh-Shiuan Liu, Shuo Wang, Hongen Xie, Tsung-Ting Kao, Karan Mehta, Xiao Jia Jia, Shyh-Chiang Shen, P. Douglas Yoder, Fernando A. Ponce, Theeradetch Detchprohm, and Russell D. Dupuis

Citation: Appl. Phys. Lett. 109, 081103 (2016); doi: 10.1063/1.4961634

View online: http://dx.doi.org/10.1063/1.4961634

View Table of Contents: http://aip.scitation.org/toc/apl/109/8

Published by the American Institute of Physics

\section{Articles you may be interested in}

Sub $250 \mathrm{~nm}$ deep-UV AIGaN/AIN distributed Bragg reflectors

Applied Physics Letters 110, 011105 (2017); 10.1063/1.4973581

Deep ultraviolet emission from ultra-thin GaN/AIN heterostructures

Applied Physics Letters 109, 241102 (2016); 10.1063/1.4971968

Composition pulling effect and strain relief mechanism in AIGaN/AIN distributed Bragg reflectors

Applied Physics Letters 98, 261916 (2011); 10.1063/1.3605681

MBE-grown 232-270 nm deep-UV LEDs using monolayer thin binary GaN/AIN quantum heterostructures Applied Physics Letters 110, 041108 (2017); 10.1063/1.4975068

Physics and polarization characteristics of $298 \mathrm{~nm}$ AIN-delta-GaN quantum well ultraviolet light-emitting diodes Applied Physics Letters 110, 071103 (2017); 10.1063/1.4976203

The effects of magnesium doping on the modal loss in AIGaN-based deep UV lasers

Applied Physics Letters 110, 081103 (2017); 10.1063/1.4977029

\section{A 1 | Applied Physics Letters}

Save your money for your research.

It's now FREE to publish with us no page, color or publication charges apply.

If your article has the

potential to shape the future of applied physics, it BELONGS in

Applied Physics Letters 


\title{
Strain management of AIGaN-based distributed Bragg reflectors with GaN interlayer grown by metalorganic chemical vapor deposition
}

\author{
Yuh-Shiuan Liu, ${ }^{1}$ Shuo Wang, ${ }^{2}$ Hongen Xie, ${ }^{2}$ Tsung-Ting Kao, ${ }^{1}$ Karan Mehta, ${ }^{1}$ Xiao Jia Jia, ${ }^{1}$ \\ Shyh-Chiang Shen, ${ }^{1}$ P. Douglas Yoder, ${ }^{1}$ Fernando A. Ponce, ${ }^{2}$ Theeradetch Detchprohm, ${ }^{1}$ \\ and Russell D. Dupuis ${ }^{1, a), b)}$ \\ ${ }^{1}$ Center for Compound Semiconductors and School of Electrical and Computer Engineering, \\ Georgia Institute of Technology, 777 Atlantic Dr. NW, Atlanta, Georgia 30332-0250, USA \\ ${ }^{2}$ Department of Physics, Arizona State University, Tempe, Arizona 85287-1504, USA
}

(Received 20 June 2016; accepted 13 August 2016; published online 25 August 2016)

\begin{abstract}
We report the crack-free growth of a 45-pair $\mathrm{Al}_{0.30} \mathrm{Ga}_{0.70} \mathrm{~N} / \mathrm{Al}_{0.04} \mathrm{Ga}_{0.96} \mathrm{~N}$ distributed $\mathrm{Bragg}$ reflector (DBR) on 2 in. diameter AlN/sapphire template by metalorganic chemical vapor deposition. To mitigate the cracking issue originating from the tensile strain of $\mathrm{Al}_{0.30} \mathrm{Ga}_{0.70} \mathrm{~N}$ on $\mathrm{GaN}$, an $\mathrm{AlN}$ template was employed in this work. On the other hand, strong compressive strain experienced by $\mathrm{Al}_{0.04} \mathrm{Ga}_{0.96} \mathrm{~N}$ favors 3D island growth, which is undesired. We found that inserting an $11 \mathrm{~nm}$ thick $\mathrm{GaN}$ interlayer upon the completion of AIN template layer properly managed the strain such that the $\mathrm{Al}_{0.30} \mathrm{Ga}_{0.70} \mathrm{~N} / \mathrm{Al}_{0.04} \mathrm{Ga}_{0.96} \mathrm{~N}$ DBR was able to be grown with an atomically smooth surface morphology. Smooth surfaces and sharp interfaces were observed throughout the structure using high-angle annular dark-field imaging in the STEM. The 45-pair AlGaN-based DBR provided a peak reflectivity of $95.4 \%$ at $\lambda=368 \mathrm{~nm}$ with a bandwidth of $15 \mathrm{~nm}$. Published by AIP Publishing.

[http://dx.doi.org/10.1063/1.4961634]
\end{abstract}

Vertical-cavity surface-emitting lasers (VCSELs) have been employed in numerous applications instead of edgeemitting lasers owing to the advantages of lower threshold current operation, circular and low-divergence output beam, and lower temperature sensitivity. Much effort has been invested in III-nitride based VCSELs for the visible and ultraviolet wavelength ranges. ${ }^{1-4}$ The performance of current-injection VCSELs strongly depends on the crystal quality of the distributed Bragg reflectors (DBRs) typically composed of epitaxially grown semiconductor materials. ${ }^{5}$ However, in the III-nitride material system, epitaxial growth of high-quality DBR structures remains an extremely difficult challenge due to the large lattice mismatch between GaN and AlN as well as the relatively low refractive index contrast of this material system. The issue can be more complicated if the target wavelength is near $\lambda=365 \mathrm{~nm}$ which is the peak emission wavelength of GaN. This is due to the fact that it is favorable to grow the active region on a GaN substrate while the choice of optically transparent material that can be epitaxially grown on GaN to form a high-reflectivity DBR without tensile-strain-induced cracking is, however, very limited. As a result, the refractive index contrast is further limited and a large number of pairs are required to achieve a UV reflectivity above $90 \%$ such as exhibited by our previously reported electrically conducting $n$-DBR. ${ }^{6}$ To avoid the cracking issue, an AIN substrate can be used instead of a GaN substrate. The disadvantage for using an AlN substrate is the strong compressive strain exerted on the active region will limit the quality of the material and further reduce the achievable internal quantum efficiency. Without

\footnotetext{
a) Author to whom correspondence should be addressed. Electronic mail: dupuis@gatech.edu

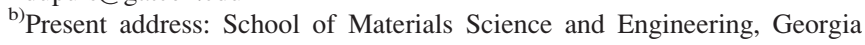
Institute of Technology, Atlanta, Georgia 30332-0250, USA.
}

high crystalline quality of the active region, the compromised quantum efficiency leads to poor device performance. To the best of our knowledge, an electrically injected VCSEL operating in this wavelength with a semiconductor DBR has not yet been reported. In this work, we report a novel strain-management method to epitaxially grow AlGaN-based DBRs on an AlN-based substrate such that it provides larger refractive index contrast than the DBRs operating in the same wavelength range grown on a GaN substrate while maintaining the strain state for high-quality active region growth. There are other approaches to achieve high-reflectivity crack-free $(\mathrm{Al}) \mathrm{GaN} / \mathrm{Al}(\mathrm{Ga}) \mathrm{N}$ DBRs and a summary of those approaches can be found elsewhere. ${ }^{7}$

The epitaxial growth was performed in a Thomas-Swan AIXTRON $6 \times 2$ in. close-coupled showerhead metalorganic chemical vapor deposition (MOCVD) reactor system. EpiPure ${ }^{\circledR}$ Trimethylaluminum $\left(\mathrm{Al}\left(\mathrm{CH}_{3}\right)_{3}, \mathrm{TMAl}\right)$ and trimethylgallium $\left(\mathrm{Ga}\left(\mathrm{CH}_{3}\right)_{3}\right.$, TMGa) were used for group III precursors while ammonia $\left(\mathrm{NH}_{3}\right)$ was used for group $\mathrm{V}$ precursor. Following the growth of an AIN template layer on the sapphire substrate, the temperature was lowered to $\sim 860^{\circ} \mathrm{C}$ to grow an $\sim 11 \mathrm{~nm}$ thick GaN interlayer. The temperature was then ramped back to $\sim 1060^{\circ} \mathrm{C}$ to grow the DBR. The purpose of this $\mathrm{GaN}$ interlayer is to manage the material strain state such that a higher quality DBR and active region can be grown on top of the AlN as reported by Wang et al. ${ }^{8}$ The DBR reported in this work consists of 45-pairs of quarter-wavelength-thick layers of undoped $\mathrm{Al}_{0.30} \mathrm{Ga}_{0.70} \mathrm{~N}$ and $\mathrm{Al}_{0.04} \mathrm{Ga}_{0.96} \mathrm{~N}$. Although silane doping was not introduced in this work, the relatively low AlN mole fraction (less than $x=0.3$ ) still provides the possibility of electrical conduction for similar Si-doped DBRs. Compared to the AlN interlayer approach reported by Waldrip et al., ${ }^{9}$ our approach utilizing a single GaN interlayer significantly reduces the required epitaxial growth time as well as 
enabling the possibility for electrical conduction while maintaining good optical reflectivity.

A detailed analysis of the crystal structure of the DBR was performed using high-angle annular dark-field (HAADF) imaging in a JEOL ARM200F scanning transmission electron microscope (STEM), operating at $200 \mathrm{kV}$. The sample was prepared by mechanical wedge-polishing, followed by Ar ion-milling at $4 \mathrm{kV}$. Figure 1 shows a crosssection HAADF image, along a $\{11 \overline{2} 0\}$ zone axis, of the 45pair $\mathrm{Al}_{0.30} \mathrm{Ga}_{0.70} \mathrm{~N} / \mathrm{Al}_{0.04} \mathrm{Ga}_{0.96} \mathrm{~N}$ DBR on a GaN interlayer on an AIN template. The entire 45-pairs of the DBR with a total thickness of $\sim 3.3 \mu \mathrm{m}$ is clearly observed. The HAADF intensity at the given detector angle can be described as ${ }^{10}$

$$
I_{H A A D F}(q)=\left(\frac{1}{2 \pi^{2} a_{0} q^{2}} Z\right)^{2}
$$

where $a_{0}$ is Bohr's radius; $Z$ is the atomic number; and $q=\frac{2 \sin (\theta)}{\lambda}$ with $\theta$ referring to the scattering angle of electrons with respect to incident electron beam. The equation indicates that the intensity is roughly proportional to $Z^{2}$; therefore in this image, the darker layers represent higher AlN mole fraction AlGaN layers, and brighter layers represent higher $\mathrm{GaN}$ mole fraction layers. Abrupt interfaces between the $\mathrm{Al}_{0.30} \mathrm{Ga}_{0.70} \mathrm{~N}$ and $\mathrm{Al}_{0.04} \mathrm{Ga}_{0.96} \mathrm{~N}$ layers are observed throughout the image. The average thickness for the $\mathrm{Al}_{0.30} \mathrm{Ga}_{0.70} \mathrm{~N}$ and $\mathrm{Al}_{0.04} \mathrm{Ga}_{0.96} \mathrm{~N}$ layers was determined to be $38.3 \mathrm{~nm}$ and $33.3 \mathrm{~nm}$, respectively. The measured thicknesses represent a close match to the intended ideal quarter-wavelength values of $37.5 \mathrm{~nm}$ and $35.4 \mathrm{~nm}$ for $\mathrm{Al}_{0.30} \mathrm{Ga}_{0.70} \mathrm{~N}$ and $\mathrm{Al}_{0.04} \mathrm{Ga}_{0.96} \mathrm{~N}$ based on the refractive index reported in the literature. ${ }^{11}$

To further study the GaN interlayer grown in between the AlN template and DBR, higher magnification images were acquired. A higher magnification cross-section image along a

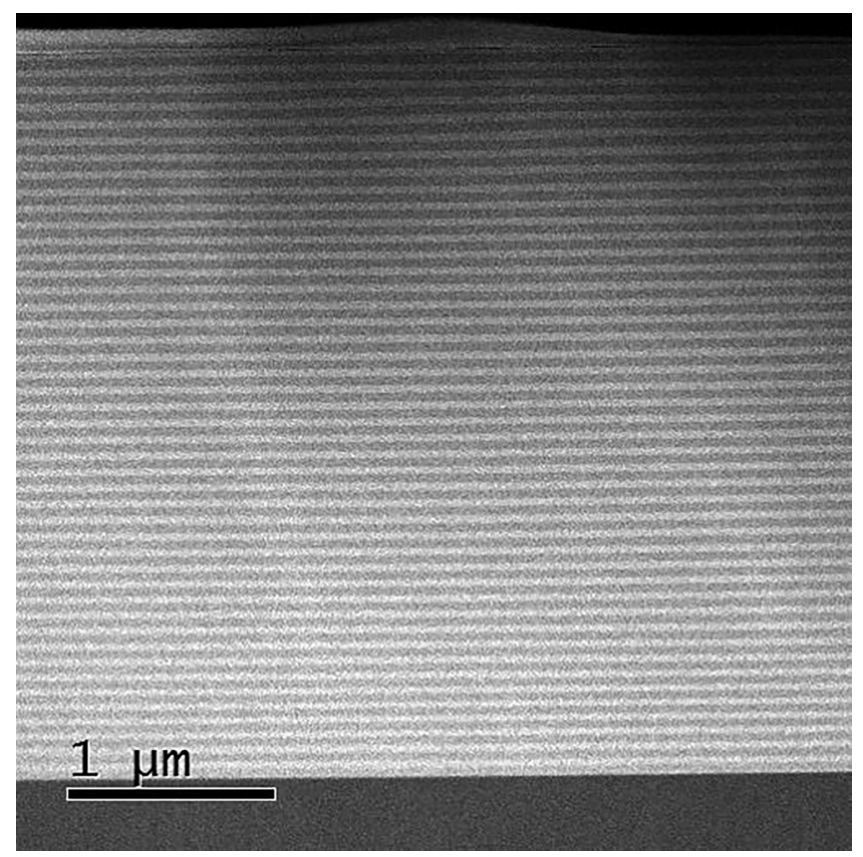

FIG. 1. Cross-section STEM-HAADF image for a 45-pair $\mathrm{Al}_{0.30} \mathrm{Ga}_{0.70} \mathrm{~N} /$ $\mathrm{Al}_{0.04} \mathrm{Ga}_{0.96} \mathrm{~N} \mathrm{DBR}$ on a $\mathrm{GaN}$ interlayer on an $\mathrm{AlN}$ template, taken along a $\{11 \overline{2} 0\}$ projection.
$\{11 \overline{2} 0\}$ zone axis including the $\mathrm{GaN}$ interlayer is shown in Fig. 2(a). A thin layer of $11 \mathrm{~nm} \mathrm{GaN}$ interlayer is clearly observed. Despite the lattice mismatch between AlN and $\mathrm{GaN}$, the thin $\mathrm{GaN}$ interlayer still maintains a smooth 2D (i.e., layer-by-layer) growth, and sharp interfaces between the AlN/ $\mathrm{GaN} / \mathrm{AlGaN}$ layers are observed. Without this thin $\mathrm{GaN}$ interlayer to manage the strain, the growth of either $\mathrm{Al}_{0.30} \mathrm{Ga}_{0.70} \mathrm{~N}$ or $\mathrm{Al}_{0.04} \mathrm{Ga}_{0.96} \mathrm{~N}$ layers on AIN would likely turn into rough surface morphology. ${ }^{12,13}$ Although the rough surface of AlGaN layers grown on AlN can potentially be smoothed out by growing a thicker AlGaN layer, such an approach is not suitable for UV DBR growth with quarter-wave thick layers. The rough surface formation from the initial nucleation mismatch would subsequently limits the maximum achievable reflectivity. ${ }^{14}$ Furthermore, the GaN interlayer also prevents the possible composition-pulling effect as a strain relief mechanism since the formation of a quasi-three-sublayer structure is also undesired and likely to occur at the AlGaN/AlN interface. ${ }^{15}$ To verify that the GaN interlayer is grown as designed,
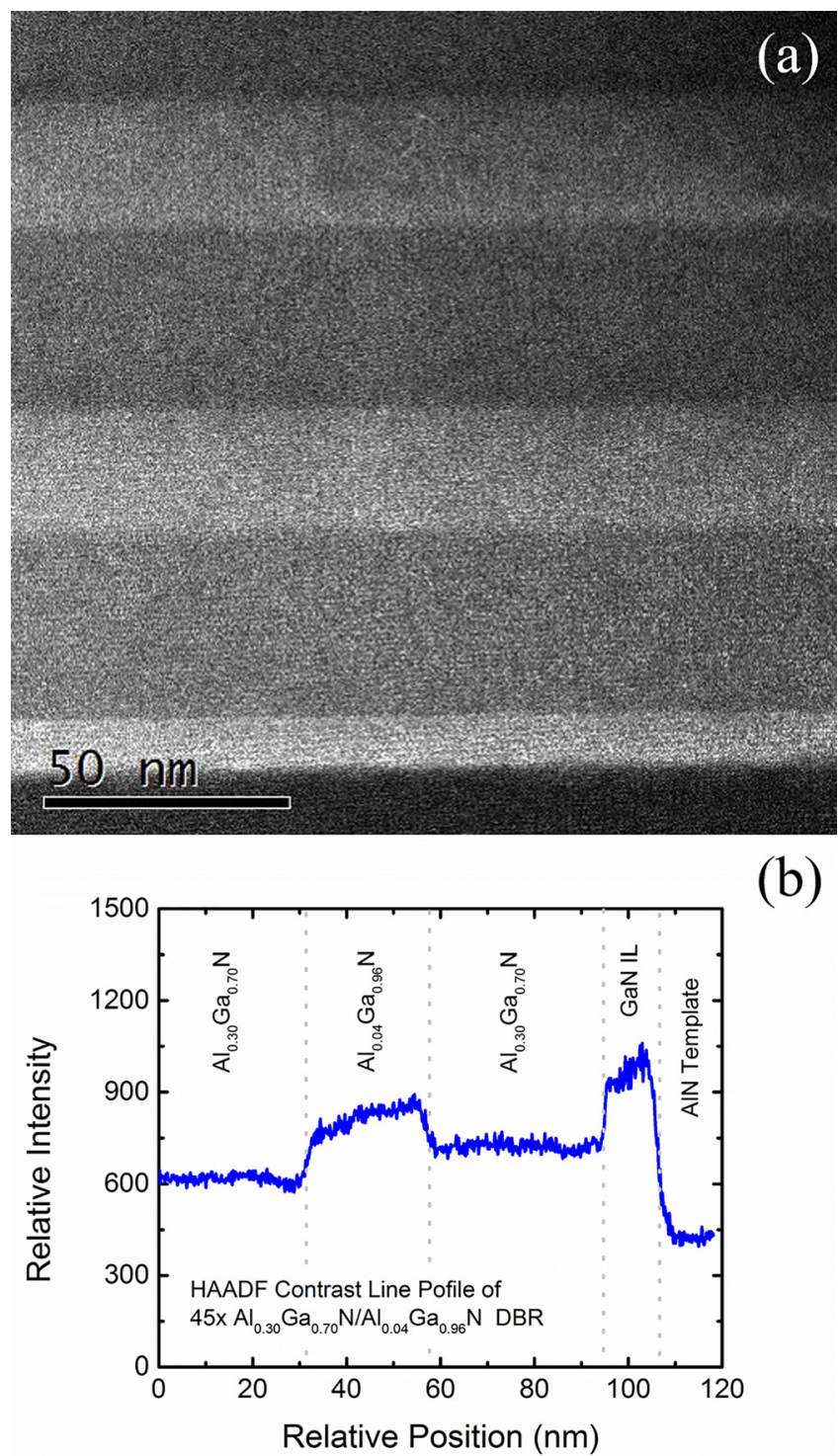

(b)

FIG. 2. (a) Magnified cross-section image along a $\{11 \overline{2} 0\}$ projection near the AlN and GaN interlayer interfaces. (b) HAADF intensity profile versus relative location for the region in (a) and the growth direction is to the left. 
further analysis on the acquired HAADF profile was performed. Fig. 2(b) shows the relative intensity profile versus the relative location of the layers measured near the firstgrown pair of the DBR. As discussed earlier, the HAADF intensity is roughly proportional to $\mathrm{Z}^{2}$ and the higher intensity refers to larger $\mathrm{GaN}$ mole fraction. In the profile, the $\mathrm{GaN} /$ AlN-template interface happens at $\sim 107 \mathrm{~nm}$ with the relatively low HAADF intensity identifying the AIN template layer. Moving along from right to left, a sharp increase in the HAADF intensity was observed which indicates our strainmanagement GaN interlayer. The GaN layer thickness measured from the HAADF scan matched our intended $11 \mathrm{~nm}$ and the rapid changes in intensity also suggest a sharp interface at the GaN/AlN interface. Notice that the composition-pulling effect as strain relief mechanism reported in Ref. 15 is not observed here and this indicates the importance of the $\mathrm{GaN}$ interlayer in reducing the strong compressive strain resulting from growth on AlN. Starting from the relative position of $\sim 95 \mathrm{~nm}$ is the beginning of the 45-pair of $\mathrm{Al}_{0.30} \mathrm{Ga}_{0.70} \mathrm{~N} /$ $\mathrm{Al}_{0.04} \mathrm{Ga}_{0.96} \mathrm{~N}$ DBR structure. The thicknesses for the DBR layers shown in this profile are slightly thinner than the average value. This was observed throughout the entire DBR structure that the average thickness per pair increases along the growth direction and this may be related to a continuous shift in the growth conditions during the growth of the DBR having a total thickness of $\sim 3.3 \mu \mathrm{m}$.

To study how the strain state changed for our 45-pair $\mathrm{Al}_{0.30} \mathrm{Ga}_{0.70} \mathrm{~N} / \mathrm{Al}_{0.04} \mathrm{Ga}_{0.96} \mathrm{~N}$ DBR grown on top of the $\mathrm{GaN}$ interlayer on AlN, the structure was characterized using reciprocal space mapping (RSM) about a high-angle asymmetry plane $\{10 \overline{1} 5\}$ of AlN taken by high-resolution tripleaxis X-ray diffractometer (XRD), shown in Fig. 3. The perpendicular and parallel axes represent the reciprocal lattice $c$ $\left(Q_{y}\right)$ axis and $a\left(Q_{x}\right)$ at the asymmetry plane $\{10 \overline{1} 5\}$, respectively. Each diffraction peak has an elongated shape due to the fact that the DBR was grown on an AlN template on a sapphire wafer instead of on a high-quality bulk AlN substrate. ${ }^{16}$ As a result, the broadening of $Q_{x}$ in the RSM originated from the relatively high dislocation density of the AIN templates was observed. The AlN template peak was found to center near $Q_{x}=2.34435 \AA^{-1}$ and $Q_{y}=6.30361 \AA^{-1}$

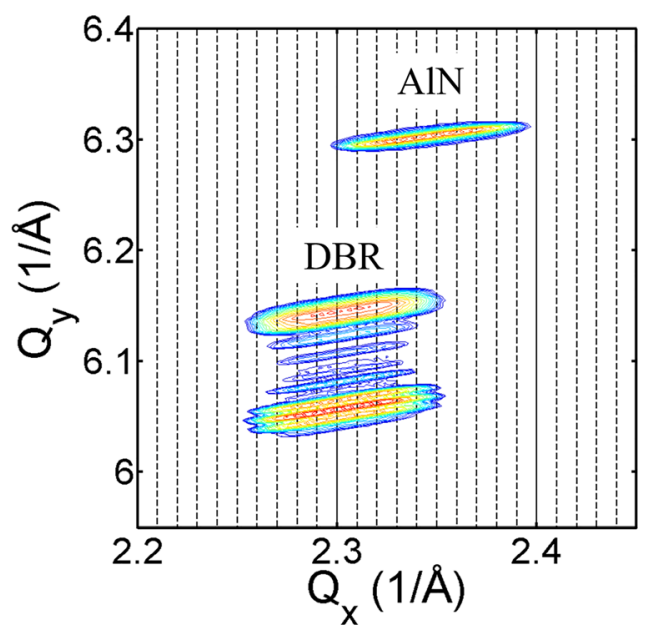

FIG. 3. (a) X-ray diffraction reciprocal-space mapping about the high-angle asymmetry plane $\{10 \overline{1} 5\}$ of AIN. while peaks for the remaining structures were found to center near $Q_{x}=2.30176 \AA^{-1}$. Since the thickness of GaN interlayer is too thin to be resolved from RSM, it is assumed that the final strain state of GaN interlayer closely matches with the lattice constant of the AlGaN DBR as the value of $Q_{x}$ for the DBR did not change gradually. This assumption will be verified with further TEM analysis utilizing the Fourier transform technique.

To verify the DBR is fully strained on the GaN interlayer and relaxation only happens at GaN interlayer/AIN interface, Fourier transform analysis was performed on the captured TEM image to acquire diffraction patterns at the interfaces. Specifically, this study focuses on the DBR/GaNinterlayer and GaN-interlayer/AIN interfaces. Fig. 4 shows the diffraction patterns along a $\{11 \overline{2} 0\}$ zone axis, acquired from a Fourier transform with vertical and lateral directions corresponding to (0002) and (1 100$)$, respectively. Since the lateral direction of the diffraction pattern reflects the changes in the in-plane direction, any relaxation from the material will be exhibited as additional diffraction spots that have different lateral spacings. As a result, we can evaluate the relaxation that occurs at the $\mathrm{DBR} / \mathrm{GaN}$ interlayer and the $\mathrm{GaN}$ interlayer/AIN interfaces from Figs. 4(a) and 4(b), respectively. The diagonal elongated diffraction spots are observed in Fig. 4(b), which is an indication of relaxation. On the other hand, Fig. 4(a) is an example of a fully strained

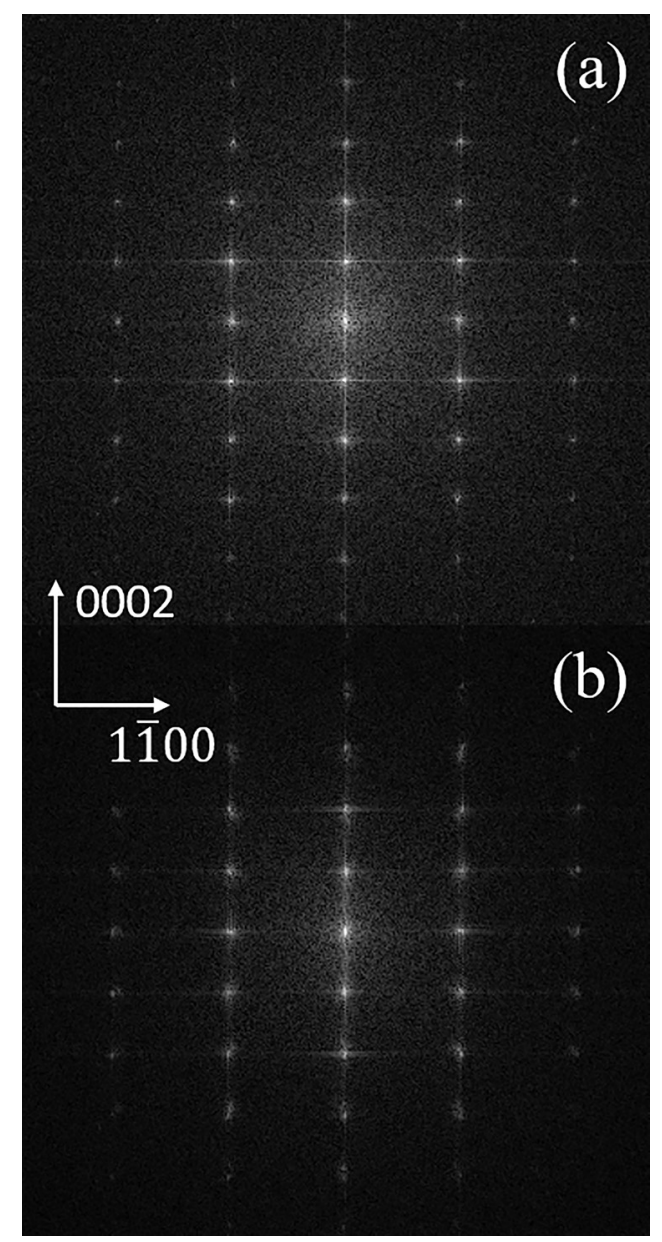

FIG. 4. Fourier transform analysis on the acquired image along a $\{11 \overline{2} 0\}$ projection in the vicinity of (a) the $\mathrm{DBR} / \mathrm{GaN}$ interlayer interface and (b) the $\mathrm{GaN}$ interlayer/AlN interface. 
structure as no changes in the in-plane direction were observed from the diffraction pattern. Thus, we can assume in the following calculations that the in-plane lattice constants of the GaN interlayer and the layers in the DBR are approximately constant since relaxation is only observed at the GaN interlayer/AIN interface from our Fourier transform analysis. The following equation relates the in-plane lattice constant $a$ and $Q_{x}$ in a hexagonal crystal system:

$$
a=\frac{4 \pi}{\sqrt{3}} \frac{\sqrt{\left(h^{2}+k^{2}+h k\right)}}{Q_{x}} .
$$

Using the above equation, we can extract the center (average) of the elongated peak, as well as the in-plane lattice constant $a$ for both AIN template and GaN interlayer, which share the same $Q_{x}$ value as the $0^{\text {th }}$ order peak of the DBR. The in-plane percentage relaxation $R_{\%}$ of the GaN interlayer with respect to the AIN template is given by

$$
R_{\%}=\frac{a_{m}(L)-a_{m}(S)}{a_{0}(L)-a_{0}(S)} \times 100,
$$

where the subscripts $m$ and 0 denote the measured and ideal values. On the other hand, the $L$ and $S$ variables represent the layer ( $\mathrm{GaN}$ interlayer in this case) and the substrate, respectively. Utilizing, in Fig. 3, the reported ideal in-plane lattice constant for AIN and GaN, ${ }^{17}$ the calculated relaxation generated via the GaN interlayer is found to be $\sim 74 \%$. The analysis with XRD and TEM clearly shows that the existence of a GaN interlayer can relax the strong compressive strain from the AlN template such that the final strain states closely match with the lattice constant of the AlGaN DBR. In addition to the observed strong relaxation, the growth of the entire DBR structure remained fully strained throughout the 45-pair DBR, which enabled the smooth surface formation as shown in the previous images.

In addition to TEM and XRD analyses, Fig. 5 shows the reflectivity spectra measured at $300 \mathrm{~K}$ by a Shimadzu UV2401PC ultraviolet-visible spectrometer with blue-solid curve. The spectrometer is equipped with halogen and deuterium lamps for visible and ultraviolet wavelength measurements, respectively. In this study, the halogen lamp was used

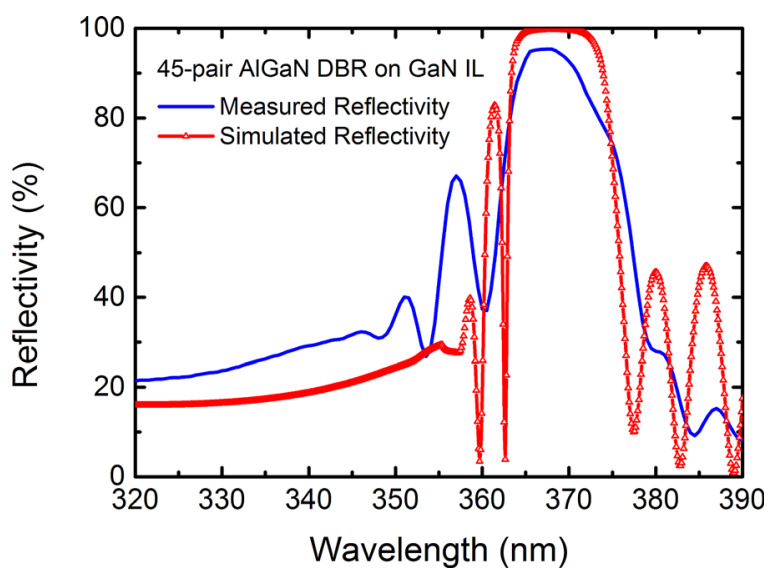

FIG. 5. Measured (blue-solid curve) and simulated (red-triangle curve) reflectivity spectra for the 45-pair $\mathrm{Al}_{0.30} \mathrm{Ga}_{0.70} \mathrm{~N} / \mathrm{Al}_{0.04} \mathrm{Ga}_{0.96} \mathrm{~N} \mathrm{DBR}$ on a $\mathrm{GaN}$ interlayer on an AlN template. to obtain the reflectivity for wavelengths longer than $\lambda>283 \mathrm{~nm}$, while the deuterium lamp was used for the reflectivity between $200<\lambda<283 \mathrm{~nm}$, using a measurement step of $0.5 \mathrm{~nm}$. Although $\mathrm{Al}_{0.04} \mathrm{Ga}_{0.96} \mathrm{~N}$ is not fully transparent near $368 \mathrm{~nm}$ due to the tail of the excitonic absorption near the material bandgap energy ${ }^{18}$ and thus has a slight absorption, the 45-pair $\mathrm{Al}_{0.30} \mathrm{Ga}_{0.70} \mathrm{~N} / \mathrm{Al}_{0.04} \mathrm{Ga}_{0.96} \mathrm{~N}$ DBR still exhibits a peak reflectivity of $95.4 \%$ with a bandwidth of $15 \mathrm{~nm}$. Furthermore, the measured average thicknesses for each of the layers obtained via TEM analysis $(38.3 \mathrm{~nm}$ and $33.3 \mathrm{~nm}$ for $\mathrm{Al}_{0.30} \mathrm{Ga}_{0.70} \mathrm{~N}$ and $\mathrm{Al}_{0.04} \mathrm{Ga}_{0.96} \mathrm{~N}$ ) were employed to simulate the ideal reflectivity curve as presented in Fig. 5 as a red-triangle curve. To account for the strain relaxation originating from the GaN interlayer based on our XRD analysis ( $\sim 74 \%$ relaxation) and the excitonic absorption from the material, the complex refractive indices were calculated according to the previous reports. ${ }^{11,19}$ The simulated reflectivity spectrum demonstrated a peak reflectivity of $99.7 \%$ with a bandwidth of $13 \mathrm{~nm}$. In the case for a DBR without a $\mathrm{GaN}$ interlayer, the peak reflectivity was slightly reduced down to $99.3 \%$ compared to $99.7 \%$ for the DBR with a GaN interlayer. Although the $\mathrm{GaN}$ interlayer can introduce additional optical absorption, the increase index contrast between the GaN interlayer and the AlN template (versus $\mathrm{Al}_{0 / 3} \mathrm{Ga}_{0.7} \mathrm{~N}$ and AlN) outweighs the penalty from increased optical loss.

In summary, we report a crack-free growth of a 45-pair $\mathrm{Al}_{0.30} \mathrm{Ga}_{0.70} \mathrm{~N} / \mathrm{Al}_{0.04} \mathrm{Ga}_{0.96} \mathrm{~N}$ distributed Bragg reflector (DBR) by metalorganic chemical vapor deposition. We found that inserting an $11 \mathrm{~nm}$-thick GaN interlayer upon the interface with the AlN template was able to properly manage the strain so that smooth low-aluminum-content $\mathrm{Al}_{\mathrm{x}} \mathrm{Ga}_{1-\mathrm{x}} \mathrm{N}$ layers were formed. The DBR material quality as well as the interfaces was studied using STEM-HAADF imaging and smooth surfaces with sharp interfaces were observed throughout the structure. Furthermore, high-resolution XRD RSM scans and diffraction patterns showed that the GaN interlayer effectively relaxes the compressive strain from the AIN and enables smooth surface formation for the subsequently grown $\mathrm{Al}_{\mathrm{x}} \mathrm{Ga}_{1-\mathrm{x}} \mathrm{N}$ layers. The 45-pair AlGaN-based DBR has a peak reflectivity of $95.4 \%$ at $368 \mathrm{~nm}$ with a bandwidth of $15 \mathrm{~nm}$.

This work was supported by the Defense Advanced Research Projects Agency under Contract No. W911NF-15-10026. This work was performed in part at the Georgia Tech Institute for Electronics and Nanotechnology, a member of the National Nanotechnology Coordinated Infrastructure, which is supported by the National Science Foundation (Grant ECCS-1542174). RDD acknowledges additional support of the Steve W. Chaddick Endowed Chair in ElectroOptics and the Georgia Research Alliance.

${ }^{1}$ T. Onishi, O. Imafuji, K. Nagamatsu, M. Kawaguchi, K. Yamanaka, and S. Takigawa, IEEE J. Quantum Electron. 48, 1107 (2012).

${ }^{2}$ Y. Higuchi, K. Omae, H. Matsumura, and T. Mukai, Appl. Phys. Express 1, 121102 (2008).

${ }^{3}$ T.-C. Lu, C.-C. Kao, H.-C. Kuo, G.-S. Huang, and S.-C. Wang, Appl. Phys Lett. 92, 141102 (2008).

${ }^{4}$ G. Cosendey, A. Castiglia, G. Rossbach, J.-F. Carlin, and N. Grandjean, Appl. Phys. Lett. 101, 151113 (2012).

${ }^{5}$ R. D. Dupuis and P. D. Dapkus, Appl. Phys. Lett. 33, 68 (1978). 
${ }^{6}$ Y.-S. Liu, A. F. M. S. Haq, T.-T. Kao, K. Mehta, S.-C. Shen, T. Detchprohm, P. D. Yoder, R. D. Dupuis, H. Xie, and F. A. Ponce, J. Cryst. Growth 443, 81-84 (2016).

${ }^{7}$ R. Butté, E. Feltin, J. Dorsaz, G. Christmann, J. F. Carlin, N. Grandjean, and M. Ilegems, Jpn. J. Appl. Phys., Part 1 44, 7207 (2005).

${ }^{8}$ T. Wang, K. B. Lee, J. Bai, P. J. Parbrook, R. J. Airey, Q. Wang, G. Hill, F. Ranalli, and A. G. Cullis, Appl. Phys. Lett. 89, 081126 (2006).

${ }^{9}$ K. E. Waldrip, J. Han, J. J. Figiel, H. Zhou, E. Makarona, and A. V. Nurmikko, Appl. Phys. Lett. 78, 3205 (2001).

${ }^{10}$ S. Bals, B. Kabius, M. Haider, V. Radmilovic, and C. Kisielowski, Solid State Commun. 130, 675 (2004).

${ }^{11}$ R. Goldhahn, C. Buchheim, P. Schley, A. T. Winzer, and H. Wenzel, Nitride Semiconductor Devices: Principles and Simulation (Wiley-VCH Verlag GmbH \& Co. KGaA, 2007), pp. 95-115.
${ }^{12}$ Z. Ren, Q. Sun, S.-Y. Kwon, J. Han, K. Davitt, Y. K. Song, A. V. Nurmikko, H.-K. Cho, W. Liu, J. A. Smart, and L. J. Schowalter, Appl. Phys. Lett. 91, 051116 (2007).

${ }^{13}$ J. D. Acord, S. Raghavan, D. W. Snyder, and J. M. Redwing, J. Cryst. Growth 272, 65-71 (2004).

${ }^{14}$ H. E. Bennett and J. O. Porteus, J. Opt. Soc. Am. 51, 123 (1961).

${ }^{15}$ B. Liu, R. Zhang, J. G. Zheng, X. L. Ji, D. Y. Fu, Z. L. Xie, D. J. Chen, P. Chen, R. L. Jiang, and Y. D. Zheng, Appl. Phys. Lett. 98, 261916 (2011).

${ }^{16}$ M. A. Moram and M. E. Vickers, Rep. Prog. Phys. 72, 036502 (2009).

${ }^{17}$ H. Morkoç, S. Strite, G. B. Gao, M. E. Lin, B. Sverdlov, and M. Burns, J. Appl. Phys. 76, 1363-1398 (1994).

${ }^{18}$ J. F. Muth, J. H. Lee, I. K. Shmagin, R. M. Kolbas, H. C. Casey, B. P. Keller, U. K. Mishra, and S. P. DenBaars, Appl. Phys. Lett. 71, 2572 (1997).

${ }^{19}$ J. Piprek, H. Wenzel, and M. Kneissl, Proc. SPIE 6766, 67660H (2007). 